\title{
Effects of cage volume and bee density on survival and nutrient intake of honeybees (Apis mellifera L.) under laboratory conditions
}

\author{
Henrika Jacomina BosuA ${ }^{1}$, Susan Wendy Nicolson ${ }^{1}$, Catherine Ruth ArCHER ${ }^{2}$, \\ Christian Walter Werner PIRK ${ }^{1}$

\footnotetext{
${ }^{1}$ Social Insects Research Group, Department of Zoology and Entomology, University of Pretoria, Hatfield, South Africa ${ }^{2}$ College of Life and Environmental Sciences, University of Exeter, Penryn Campus, Cornwall, UK
}

Received 21 November 2017 - Revised 25 June 2018 - Accepted 7 August 2018

\begin{abstract}
Laboratory experiments are vital to exploring the causes of pollinator loss, but for these experiments to be informative, they should attempt to replicate the hive environment and conserve social interactions. It is unclear how honeybee density and group size affect survival and behaviour in the laboratory. We manipulated cage volume $(125-1312 \mathrm{ml})$ and honeybee group size (10-180 bees) and tested the effects on survival and feeding behaviour. Bees were allowed to regulate their intake from two liquid diets with dry ingredient protein: carbohydrate (P:C) ratios of 0:1 and 1:50 $(w / w)$. Intake was consistent across cages, showing that feeding behaviour is largely unaffected by cage conditions. High survival was recorded in cages with a volume of $2.08 \mathrm{ml} / \mathrm{bee}$, which falls within the natural range of $1.9-3.8 \mathrm{ml} / \mathrm{bee}$ in nest sites, and in groups of $<60$ bees. We suggest that cage volume is more important than group size, and that cage dimensions should be adjusted so that each bee has $<3.0 \mathrm{ml}$ of space.
\end{abstract}

cage design / laboratory studies / nutrient regulation / survival / honeybee

\section{INTRODUCTION}

Inside the hive, the high temperature and humidity required for rearing brood are maintained by thermoregulation of worker bees (Oertel 1949; Jones et al. 2004; Human et al. 2006). However, the volume of the nest and its insulating properties will determine the effort required by bees to keep the internal conditions stable, and wild colonies make use of this criterion to select nest sites. Wild colonies selected nest sites with volumes of between 30 and $60 \mathrm{~L}$, from which the average available space per bee under natural conditions is calculated between 1.9 and $3.8 \mathrm{ml} /$ bee by adjusting for swarm size (Seeley and Morse

Corresponding author: H. Bosua, henrika.bosua@zoology.up.ac.za Manuscript editor: Bernd Grünewald
1976, McNally and Schneider 1996, Vaudo et al. 2012 McMenamin et al. 2017). Swarms also selected smaller nest sites in apiary conditions (McMenamin et al. 2017). In Kenyan apiaries, Langstroth hives with a volume of $40 \mathrm{~L}$ are preferred by migrating swarms over the larger Kenyan top bar hives $(52.5 \mathrm{~L})$ and traditional $\log$ hives (42 L) (Crane 1994; McMenamin et al. 2017). Under laboratory conditions, the temperature and humidity can be controlled by keeping bees in temperature-controlled incubators, while the volume of the nest site can be replicated through the use of specialised hoarding cages to house honeybees in groups (Williams et al. 2013).

Another important environmental factor to consider when studying honeybees is the social interactions in the hive. Bees are eusocial insects and their behaviour relies on social interactions between colony members (Nowak et al. 2010; Howard and Thorne 2010; Winston and Michener 1977). Social interactions of adult 
worker honeybees include trophallaxis (feeding each other, reviewed by Crailsheim 1992), the waggle dance directing other bees to forage (von Frisch and Lindauer 1956) and huddling together in groups to thermoregulate (Lindauer 1955). These social interactions shape individual honeybee behaviour, for example, nutrient gathering behaviour of forager bees is influenced by the composition of the trophallactic secretions received from nurse bees (Camazine et al. 1998; Schott et al. 2017) or thermoregulation within the brood nest (Basile et al. 2008). This means that in a hive social interactions are necessary for bees to regulate colony temperature, find forage and care for young. Therefore, in any experiment that aims to study honeybee behaviour, it is vital that bees are housed in groups so that the social interactions are preserved.

Group size could have a pronounced effect on the behaviour of caged bees (c.f. Hepburn et al. 2014). For example, when the effects of toxins are studied in cage experiments, some bees will feed directly on the available diet while others are fed through trophallaxis, as in the hive (Brodschneider et al. 2017). Since bees get exposed to toxic compounds through their diet, this social interaction could lead to an unequal toxic exposure between nest mates, with the bees feeding directly on the diet having a higher exposure (Brodschneider et al. 2017). These authors found that larger test groups of bees distribute food containing toxic compounds more evenly among individual bees, suggesting that group size of caged bees could affect the reliability of pesticide studies. Group size can further affect survival and the amount of hoarding (Rinderer and Rinderer and Baxter 1978), as well as task allocation and physiological processes like wax secretion and egg laying (Hepburn et al. 2014).

While group size of bees can clearly have a huge effect on bee behaviour, very few aspects of how cage design affects honeybee survival and behaviour in laboratory conditions have been studied. Survival under laboratory conditions is influenced by cage design and cage size (Köhler et al. 2013). Cages constructed from a variety of different materials, shapes and sizes have been tested and cage type affected honeybee survival (Williams et al. 2013; Huang et al. 2014), but the dimensions of the cages in these experiments were not standardised and the available space per bee was not consistent. Comparing these cage designs is also problematic because the volume of the cages and the type of material (which could influence ventilation, insulation and behaviour) were not standardised. Another part of cage design that can affect the outcomes of laboratory studies is the addition of feeders (Huang et al. 2014) and wax on which bees can aggregate, although the latter is not a requirement in all types of experiments. Bees survive better when natural comb is used rather than wax sheeting (Köhler et al. 2013). However, storage of food in the provided comb could skew measurements of consumption.

This lack of standardisation in cage design complicates the comparison of results between different laboratories and could explain some of the variable results produced. As an example, in research exploring how the ratio of nutrients fed to bees affects their survival, very different dietary optima have been identified in different laboratories (Archer et al. 2014a, b; Paoli et al. 2014). One possible explanation for these differences could be physiological differences between the subspecies of bees studied, as when honeybees of African and European origin utilise the protein in artificial diets differently (Morais et al. 2013). These differences may also reflect differences in diet preparation, with researchers using agarbased (Archer et al. 2014a) or liquid (Paoli et al. 2014) diets. Alternatively, differences may reflect variation in the size of hoarding cages used to house bees during the experiments and the group size of the bees in the cages.

Here, we examine the effects of cage size and honeybee density on the survival and food intake of Apis mellifera scutellata in laboratory studies. To control for the effect of nutrition on survival, bees were provided with a choice of diets (a 50\% sugar solution as well as a protein containing solution) allowing them to regulate their nutrient intake as they would in natural conditions from nectar and pollen respectively. The aim is to improve our understanding of how the density of honeybees and the volume available to honeybees affect survival and consumption parameters which will also provide data to guide the design of future experiments in which hoarding cages are used. 


\section{METHODS}

\subsection{Bees and cages}

Bees were obtained from five colonies in the University of Pretoria apiary. Frames with sealed brood were removed from the selected colonies and taken to the laboratory where they were incubated at $35{ }^{\circ} \mathrm{C}$ (Memmert $\mathrm{GmbH}+$, INE550, Schwabach, Germany) and 55-65\% RH. Adult bees were collected from the frames within $24 \mathrm{~h}$ of emergence and transferred to clear cubic, plastic cages (Polyvinyl chloride plastic gift boxes, Plastilon Packaging Company, South Africa). These were modified to house bees such that each of the four sides had 25 ventilation holes $(\sim 1 \mathrm{~mm}$ diameter) drilled into the sides and three larger holes ( $\sim 10 \mathrm{~mm}$ diameter) were made on the bottom of the front panel for the two food tubes and one water tube (Figure 1). The location of the ventilation holes spread out over the area of the four opposite sides, allowed for adequate ventilation and air flow. Food was provided in Eppendorf tubes with four holes $(\sim 1 \mathrm{~mm})$ drilled along the top, to allow access to the feeding solution. All cages were kept in dark incubators (Memmert GmbH+, INE550, Schwabach, Germany), and hive conditions were mimicked by maintaining the temperature at $35{ }^{\circ} \mathrm{C}$ as well as keeping at a high humidity $(55-65 \% \mathrm{RH})$ by placing trays of water in the incubator.

\subsection{Cage size}

Each cage contained bees from only one of the five colonies, and so is one replicate. Therefore, five replicates were set up for each cage volume tested (one for each colony). These cages were cubic in design and varied only in volume: $125 \mathrm{ml}, 216 \mathrm{ml}, 512 \mathrm{ml}, 729 \mathrm{ml}$ and $1312 \mathrm{ml}$. The space available for each individual bee in different cage sizes ( $\mathrm{ml} / \mathrm{bee})$ is given in Table I. In previous experiments, we have used hoarding cages with volumes of $216 \mathrm{ml}$ (Archer et al. 2014b) and $523 \mathrm{ml}$ (Köhler et al. 2013) so, the cage volumes selected are representative of previously used cages as well as including both larger and smaller volumes. For each cage volume tested, we included an evaporation control without any bees, giving a total of 30 cages.

\subsection{Honeybee density}

To determine the effect of density on honeybee survival, a clear plastic cage with a set volume of $512 \mathrm{ml}(8 \times 8 \times 8 \mathrm{~cm})$ was selected, as this was the closest to the volume of the Perspex hoarding cages used in our previous experiments $(523 \mathrm{ml}$, Altaye et al. 2010, Archer et al. 2014b). Six densities of bees were selected: 10, 30, 60, 100, 150 and 180 bees per cage. The 30 bee density was selected based on the highest survival in a previous density study (Rinderer and Baxter 1978) while 60 and 100 were selected as those are commonly used in our laboratory (Altaye et al. 2010; Köhler et al. 2013; Archer et al. 2014b). The remaining densities $(10,150$ and 180) were selected to represent lower and upper extremes. For each density-tested five replicates, each representing bees from a different colony was set up. Each cage contained bees from a single colony so that on colony was one replicate and five replicates were set up for each density tested. The space available for each individual bee at different densities $(\mathrm{ml} /$ bee) is given in Table I. Each hoarding cage was modified from the previous design to contain five feeding tubes instead of three, and cages containing higher densities of bees (100, 150 and 180 bees) were provided with four food tubes (two containing protein solution and two sugar solution) and one tube containing water. Bees consume approximately 10-15 mg carbohydrate and less than $1 \mathrm{mg}$ protein per day (Bosua 2017), and this experimental set up makes provision for between 25 and $50 \mathrm{mg}$ dry food per bee per day. The extra feeding tubes were added to prevent crowding at the feeding tubes. Cages with the lower densities of bees $(10,30$ and 60 bees) were provided with two food tubes (one containing protein solution and one sugar solution) and one water tube, as well as two empty tubes to ensure the same amount of space was being utilised by food tubes across the different cages. Evaporation control cages were set up, 


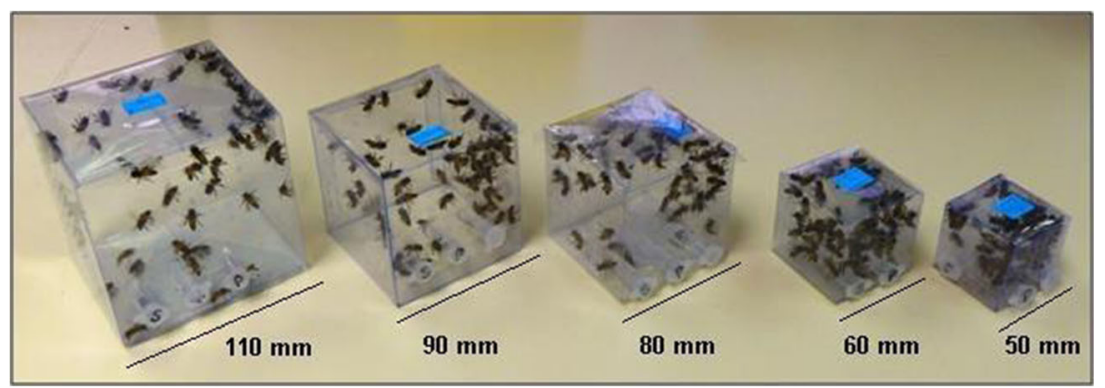

Figure 1 Comparison of the different cage sizes with 60 bees in each cage. All cages had ventilation holes and openings for feeding tubes. Linear dimensions of the cubic cages are displayed beneath each cage.

and the average evaporation determined was subtracted from the food and water measurements to correct for the effect of evaporation.

\subsection{Food preparation}

All cages of bees were fed $50 \% \mathrm{w} / \mathrm{w}$ sucrose solution as well as a protein containing solution with a $\mathrm{P}: \mathrm{C}$ ratio of $1: 50$ (diet contained $50 \%$ water, $49 \%$ carbohydrate and $1 \%$ protein). PeptoPro ${ }^{\mathrm{TM}}$ (DSM nutritional products South Africa (Pty) Ltd., Isando, South Africa) was used as a protein source while granulated sucrose was used a source of carbohydrate. PeptoPro ${ }^{\mathrm{TM}}$ is a hydrolysed form of casein and is soluble in water, making it suitable for liquid diets. The P:C 1:50 ratio was chosen as the liquid diet that led to the highest survival during a previous experiment comparing survival and consumption on a range of P:C ratios (Bosua et al. 2017; unpublished thesis).

\subsection{Survival and consumption measurements}

Consumption was measured across the different cage sizes and honeybee densities to control for the effects of nutrition on survival. Consumption was measured daily by weighing the food and water tubes before placing them in the cages and after removal from the cage after $24 \mathrm{~h}$. To control for evaporation, we placed tubes in empty cages, with one control cage for each cage size and for each bee density. For the evaporation controls, the daily difference in weight between tubes (for sugar, protein

Table I. The relative volume per bee and percentage survival after 14 days for each of the cage sizes and densities. Each of the different cage sizes contained 60 bees, while the different densities of bees were housed in a cage with a 512-ml volume. The total cage volume was divided by the number of bees in each cage to get the volume/bee. Different letters indicate significant differences

\begin{tabular}{lllllll}
\hline \multicolumn{2}{c}{ Cage size (constant: 60 bees per cage) } & & \multicolumn{3}{c}{ Density (constant: 512-ml cage volume) } \\
\cline { 1 - 1 } Cage size (ml) & $\begin{array}{c}\text { Volume } \\
(\mathrm{ml} / \mathrm{bee})\end{array}$ & Survival (\%) $\pm \mathrm{SD}$ & & $\begin{array}{c}\text { Density } \\
\text { (no. of bees) }\end{array}$ & $\begin{array}{c}\text { Volume } \\
(\mathrm{ml} / \mathrm{bee})\end{array}$ & Survival (\%) \pm SD \\
\hline 125 & 2.08 & $77.33 \pm 9.66^{\mathrm{a}}$ & & 10 & 51.20 & $62.00 \pm 22.80^{\mathrm{b}}$ \\
216 & 3.60 & $62.00 \pm 10.18$ & & 30 & 17.07 & $56.67 \pm 18.10^{\mathrm{b}}$ \\
512 & 8.53 & $55.33 \pm 20.61$ & & 60 & 8.53 & $62.67 \pm 20.74^{\mathrm{b}}$ \\
729 & 12.15 & $62.00 \pm 12.91$ & & 100 & 5.12 & $36.20 \pm 29.79^{\mathrm{c}}$ \\
1312 & 21.87 & $60.67 \pm 16.71$ & & 150 & 3.41 & $23.07 \pm 41.35^{\mathrm{c}}$ \\
& & & & 180 & 2.84 & $41.11 \pm 35.47^{\mathrm{c}}$ \\
\hline
\end{tabular}


and water tubes) was taken as the evaporation. The final consumption in the experimental cages was taken as the difference in weight before and after feeding to bees, minus the evaporation measured for the associated food (i.e., protein or sugar) in the same cage size or bee density. Both protein and carbohydrate consumption were calculated as mg per bee per day. The survival of honeybees in all cages was measured daily over 14 days, thus obtaining a survival measurement that tracks the physiological transition from hive bees to foragers, by collecting and counting the dead bees in each cage. During the density experiments, dead bees were replaced daily to keep the density constant. At the onset of the experiment, a spare cage containing between 100 and 200 bees was set up for each of the colonies used. The bees from this spare cage were used to replace the dead bees in the experimental cages, ensuring that the replacement bees were the same age as the experimental bees. All bees still alive after 14 days were frozen at $-20{ }^{\circ} \mathrm{C}$.

\subsection{Data analyses}

The survival data for all experiments were analysed using Kaplan Meier survival regression, and Gehan's Wilcoxon paired $t$ tests were used to test for differences between densities as well as cage sizes. A Bonferroni adjusted $\alpha$ value of $<0.001$ was taken as significant to control for multiple testing on survival data. Cage size and colony were used as explanatory variables in the cage size experiment, while density and colony were selected as explanatory variables for the density experiment. All consumption data (protein and carbohydrate consumption) were tested for normality using the Kolmogorov-Smirnov test. Data that were non-normally distributed were analysed with main effects ANOVAs with colony and cage size or density used as explanatory variables. Differences in nutrient intake were analysed between different cage sizes and honeybee densities using Bonferroni post-hoc tests. All statistical analyses were conducted in Statistica (StatSoft, Inc., Tulsa, OK, USA; version 64).

\section{RESULTS}

\subsection{Cage size}

\subsubsection{Survival}

During the course of the 14-day experiment, survival of the 60 bees differed between the cage sizes (Kaplan Meier, $\chi 2=50.00, \mathrm{df}=4$, $p<0.001$ ) and colonies (Kaplan Meier, $\chi 2=$ 205.86, $\mathrm{df}=4, p<0.001$ ) (Figure 2). The $125 \mathrm{ml}$ and $512 \mathrm{ml}$ cages had the highest and lowest percentage survival respectively $(125 \mathrm{ml}$, $77.33 \pm 9.65 ; 512 \mathrm{ml}, 55.33 \pm 20.60$, Table I), and survival in these cages differed from that in the other cage volumes (Table II; Figure 2). In the remaining three cage volumes, the percentage survival did not differ $(216 \mathrm{ml}, 62.00 \pm 10.18$; $792 \mathrm{ml}, 62.00 \pm 12.09$ and $1312 \mathrm{ml}, 61.67 \pm$ 16.71; Table II; Figure 2).

\subsubsection{Consumption}

Honeybees were allowed to regulate their intake from two liquid diets, a protein containing diet with a $\mathrm{P}: \mathrm{C}$ ratio of $1: 50$ and a pure sucrose $\operatorname{diet}(\mathrm{P}: \mathrm{C} 0: 1)$. Colony had no significant effect on either daily (MANOVA, $\mathrm{df}=4, F=1.45, p=$ 0.1706 ) or cumulative (MANOVA, $\mathrm{df}=4, F=$ $1.77 p=0.0800$ ) consumption of bees housed in different sized cages. Cage volume had a significant influence on the daily amount of protein (MANOVA, df $=4, F=5.634, p<0.001$ ) and carbohydrate (MANOVA, df $=4, F=5.634$, $p<0.001)$ consumed by bees. Daily consumption of both nutrients was not significantly different in the $125 \mathrm{ml}$ and $216 \mathrm{ml}$ cages (carbohydrate: Bonferroni $=21.13, \mathrm{df}=4$, n.s., protein: Bonferroni $=21.13, \mathrm{df}=4$, n.s.) or between the 512-, 729- and 1312-ml cages (Bonferroni $=$ 21.13, $\mathrm{df}=4$, n.s.); however, there was some significant differences between these groups.

While there was no significant difference in the 14-day cumulative carbohydrate consumption between the different cage sizes tested (Bonferroni = $3003.7, \mathrm{df}=4, p>0.05$ ), cumulative protein consumption was lower in both the 512-ml cage (Bonferroni $=0.30, \mathrm{df}=4, p>0.05$ ) and the $1312-\mathrm{ml}$ cage $($ Bonferroni $=0.30, \mathrm{df}=4$, 


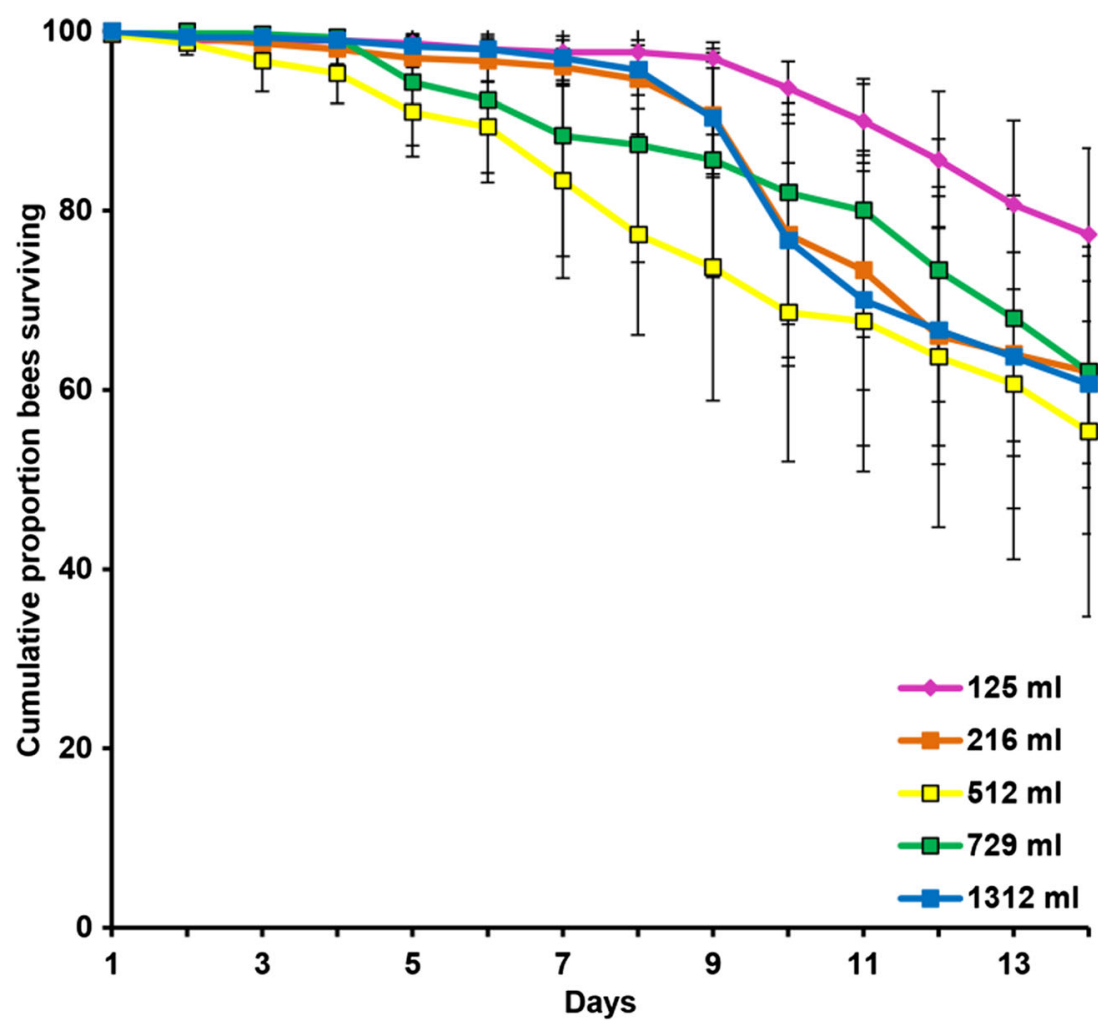

Figure 2 Proportion surviving ( \pm SD) over 14 days for 60 bees in cages of different volumes. Results were averaged for five replicate cages per volume tested, with each cage containing bees from a single colony.

$p>0.05)$ than in the remaining cage sizes. Nutrient intake ratios were consistent between the different cage sizes with all cages of bees converging on a similar P:C ratio of 1:105 (Figure 3).

Table II. Survival was compared across different cage sizes using Gehan's Wilcoxon tests and the resulting $p$ values are presented here. An $\alpha$ value of $\alpha<0.001$ is taken as significant to account for multiple comparisons. Italic values are significant

Gehan's Wilcoxon comparisons, $p$ values

\begin{tabular}{lllll}
\hline Cage size & $216 \mathrm{ml}$ & $512 \mathrm{ml}$ & $729 \mathrm{ml}$ & $1312 \mathrm{ml}$ \\
\hline $125 \mathrm{ml}$ & $<0.001$ & $<0.001$ & $<0.001$ & $<0.001$ \\
$216 \mathrm{ml}$ & & $<0.001$ & 0.81 & 0.53 \\
$512 \mathrm{ml}$ & & & 0.01 & 0.02 \\
$729 \mathrm{ml}$ & & & & 0.50 \\
$1312 \mathrm{ml}$ & & & & \\
\hline
\end{tabular}

\subsection{Density}

All cages in the density experiment became dirty from traces of dried diet stuck to the sides, with the amount increasing as the group size of bees increased. In groups of 100 or more, bees produced wax which also accumulated against the sides of the cages.

\subsubsection{Survival}

During the 14-day experiment, honeybee survival was significantly influenced by the density of bees in the cage (Kaplan-Meier, $\chi 2=142.42$, $\mathrm{df}=5, p<0.001$ ) as well as the colony (KaplanMeier, $\chi 2=544.26$, df $=4, p<0.001)$. Bees survived longest when kept in groups of between 10 and 60 individuals (Figure 4). Survival was not significantly different between the groups of 10 , 30 and 60 bees $(10,62.00 \pm 22.80 ; 30,56.67 \pm$ $18.10 ; 60,62.67 \pm 20.73$; Gehan Wilcoxon $=$ 


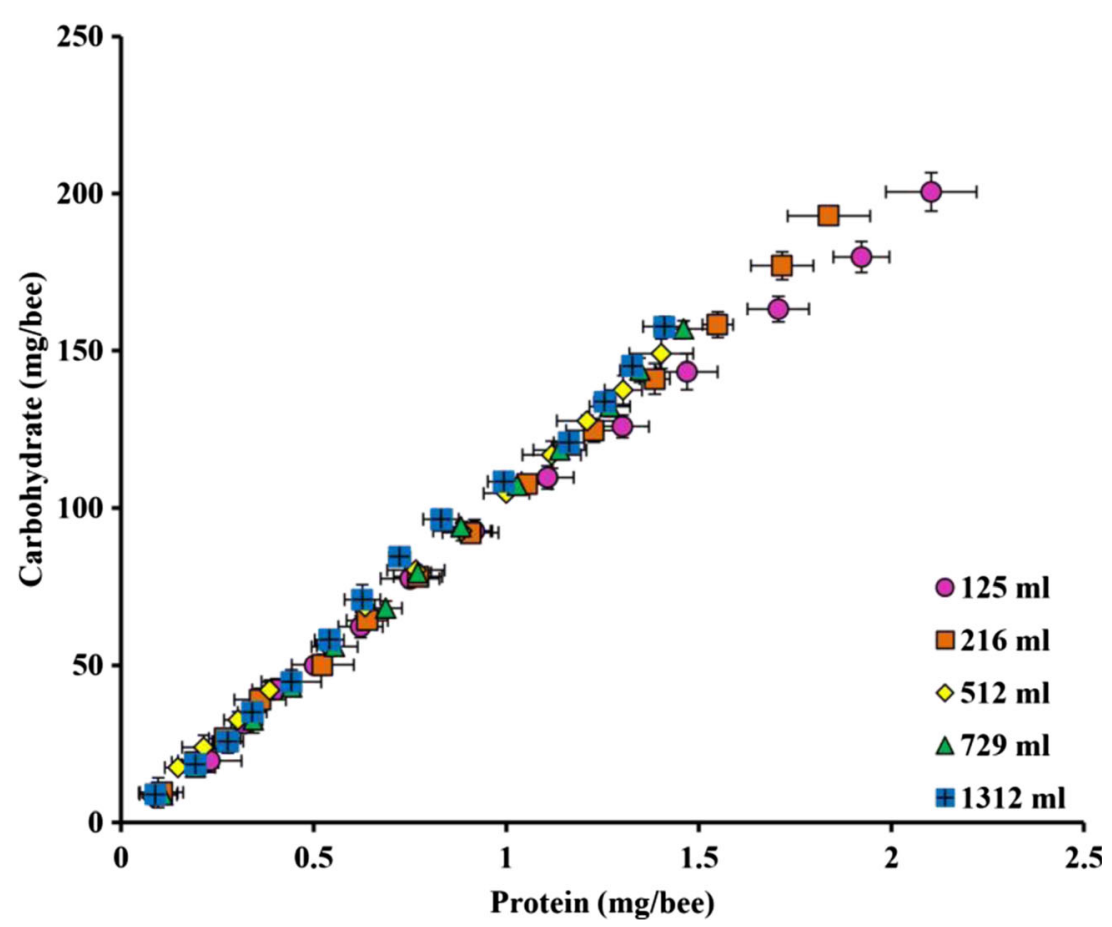

Figure 3 Cumulative carbohydrate and protein consumption $( \pm \mathrm{SD}$ ) over 14 days for 60 bees in cages with different volumes. Results were averaged for five replicate cages per volume tested, with each cage containing bees from a single colony. Bees were simultaneously fed two diets with P:C ratios of 0:1 and 1:50.

$0.8492, \mathrm{df}=5, p>0.001)$ while survival differed significantly between these and the remaining densities of bees $(100,36.20 \pm 29.79,150,23.07$ $\pm 41.35,180,41.11 \pm 35.47$ : Table III; Figure 4).

To further test for the effect of colony, survival was compared between the cage size and the density experiment. Where the experimental conditions of cage size and honeybee density were similar (60 bees in a cage with $512 \mathrm{ml}$ volume), survival was not significantly different (Gehan Wilcoxon $=4.3613, \mathrm{df}=1, p<0.001)$.

\subsubsection{Consumption}

Honeybee density affected neither daily nor cumulative consumption of either protein (daily: MANOVA, $\mathrm{df}=5, F=0.158, p>0.001$; cumulative: MANOVA, $\mathrm{df}=5, F=0.4048, p>0.001$; Figure 5) or carbohydrate (daily: MANOVA, $\mathrm{df}=$ 5, $F=65.473, p>0.001$; cumulative: MANOVA, $\mathrm{df}=5, F=3988.9, p>0.001$; Figure 5) significantly. However, two of the five colonies had higher daily carbohydrate consumption than the others (MANOVA, df $=4, F=$ $65.473, p=0.0172$ ). Daily protein consumption was not significantly different between the different colonies (Bonferroni $=0.1587$, $\mathrm{df}=4, p>0.001$ ), but over 14-day periods, three of the colonies showed higher protein consumption than the rest (Bonferroni $=$ 0.40479, df $=4, p<0.001)$.

\section{DISCUSSION}

Cage size and honeybee density within a cage affect honeybee survival and nutrient intake in laboratory conditions. Cage size only affected the cumulative protein consumption in the 512-ml and 1312-ml cages where bees consumed less protein than the rest of the cage sizes. Meanwhile, honeybee density in itself did not significantly affect the amount of nutrients consumed. However, density and colony interacted in affecting protein consumption, 


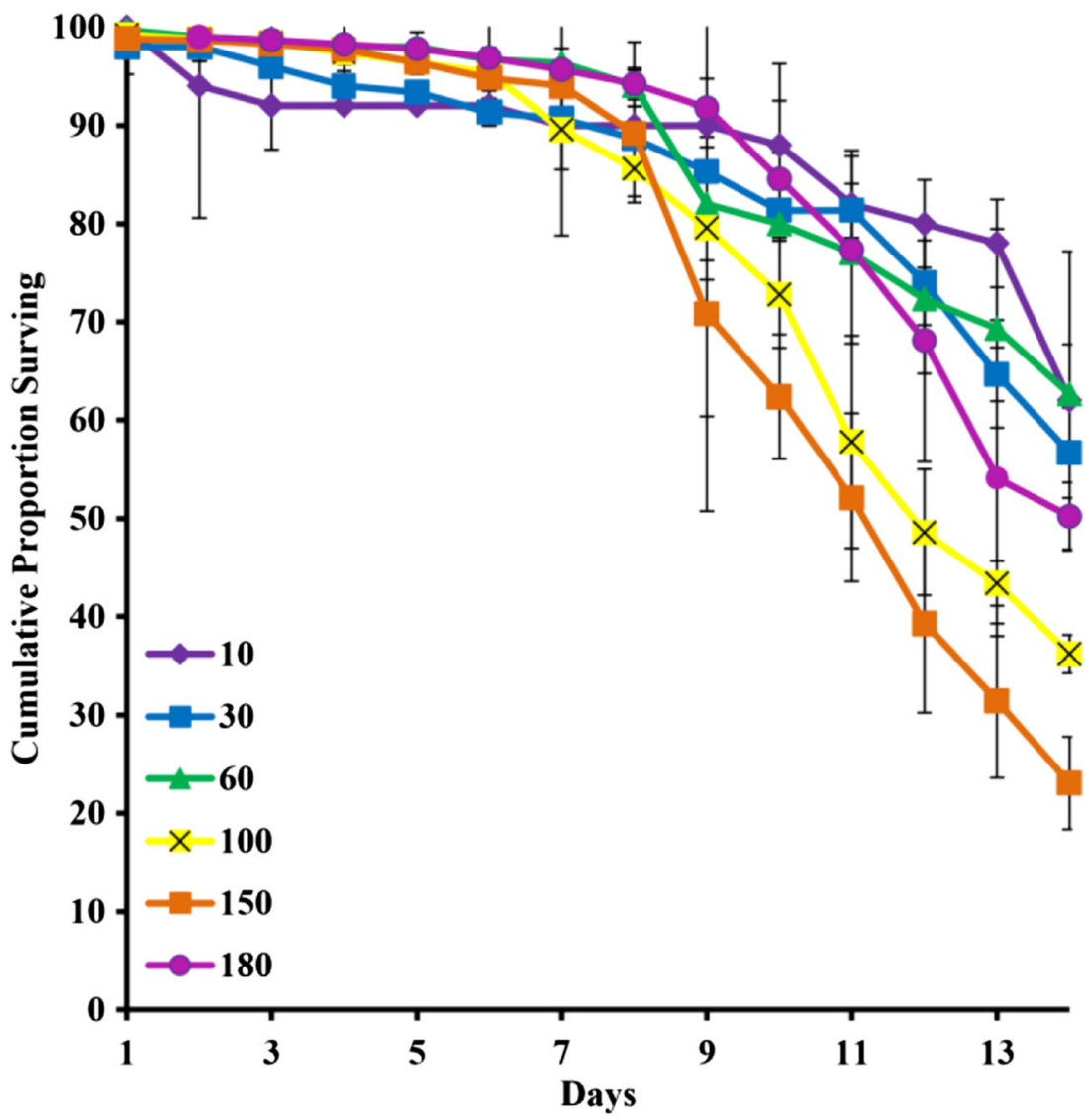

Figure 4 Survival curve $( \pm$ SD) over 14 days for different densities of honeybees in a standardised cage size $(512 \mathrm{ml})$. Results were averaged for five replicate cages per volume tested, with each cage containing bees from a single colony.

suggesting that there are some genetic differences in nutrient consumption in relationship to density.
However, despite these differences in consumption, bees were found to consume similar amounts and ratios of macronutrients $(\mathrm{P}: \mathrm{C}$

Table III. Survival was compared across different densities of honeybees using Gehan's Wilcoxon tests and the $p$ values are presented here. An $\alpha$ value of $\alpha<0.001$ is taken as significant to account for multiple comparisons. Italic values are significant

Gehan's Wilcoxon comparison, $p$ values

\begin{tabular}{|c|c|c|c|c|c|}
\hline Density & 30 & 60 & 100 & 150 & 180 \\
\hline 10 & 0.40 & 0.77 & $<0.001$ & $<0.001$ & $<0.001$ \\
\hline 30 & & 0.40 & $<0.001$ & $<0.001$ & $<0.001$ \\
\hline 60 & & & $<0.001$ & $<0.001$ & $<0.001$ \\
\hline 100 & & & & $<0.001$ & $<0.001$ \\
\hline 150 & & & & & $<0.001$ \\
\hline 180 & & & & & \\
\hline
\end{tabular}




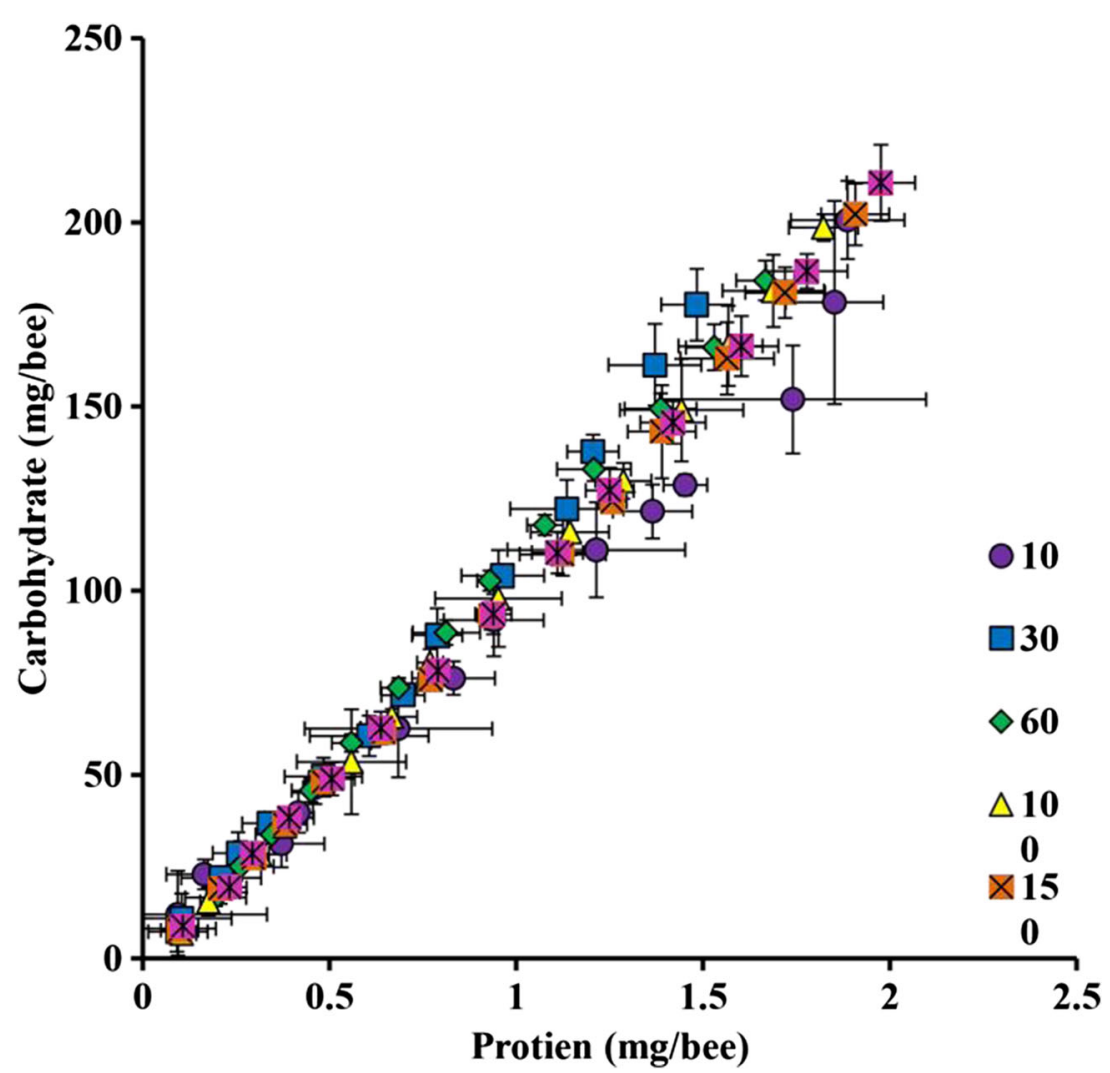

Figure 5 Cumulative protein and carbohydrate consumption $( \pm \mathrm{SD})$ for five colonies of honeybees fed a mixture of P:C 1:50 and P:C 0:1 diets for 14 days. The different colours represent the densities of bees in the cage.

$1: 105)$ among the different cage sizes and different densities, thus ruling out nutrition as the main factor affecting survival in this experiment. This suggests that the differing data on nutrient regulation found in similar nutritional studies (Archer et al. 2014a, b; Paoli et al. 2014) are not caused by differences in cage size or honeybee density, but may be due to differences in diet preparation. Indeed, the intake ratio of P:C 1:105 determined on the liquid diets used in this experiment is more similar to the P:C 1:115 determined by Paoli et al. (2014) than to the P:C 1:6.5 determined on the agar diet of Archer et al. (2014a, b).

Bees survived best in the cage with the smallest volume, when they were in close proximity to each other and had limited space per individual. The smallest cage with $2.08 \mathrm{ml} /$ bee fits within the ranges of natural conditions as described for European bees (1.9-3.8 ml/bee,
Seeley and Morse 1976)) and African bees (1.89-2.1 ml.bee- ${ }^{1}$, McNally and Schneider 1996, Vaudo et al. 2012), which supports the assumption that honeybees will perform best under conditions that mimic their natural surroundings. Survival in our experiment was very similar in cages where the available volume per bee was more than $2 \mathrm{ml} / \mathrm{bee}$. Nest site size could also be a factor that influences site selection by swarms. A recent study on swarm occupation of three different hive types in Kenya showed that the largest hive tested (Kenyan top bar hive-52.5 L) was the least preferred, with more swarms occupying the smaller Langstroth and $\log$ hives (McMenamin et al. 2017). Wild swarms of African bees also selected nest sites which were smaller (39 L) than the $44 \mathrm{~L}$ manmade Langstroth hives used by beekeepers (Vaudo et al. 2012). 
Small cages simulate high-density conditions. High densities can have several advantages in the hive environment, such as facilitating the social interaction of thermoregulation. Younger bees (12 days old) have lower thoracic temperatures than older bees and when clusters form they remain on the inside of these clusters, while older bees are found on the outer edges (Harrison 1987), suggesting that thermoregulation is not as efficient in younger bees. The workers responsible for the energetically expensive thermoregulatory behaviour in the hive are usually positioned over the brood cells and receive food in the form of trophallactic secretions from donor bees (Basile et al. 2008). The more donor bees there are, the quicker thermoregulating bees can be 'refuelled' and the more efficient thermoregulation will be. The close proximity of the bees to one another could also result in social interactions such as trophallaxis occurring more frequently. Hormonal changes and subsequent behavioural development were also influenced by the frequency of workerworker interactions in a study of bees in different group sizes (Huang and Robinson 1992), suggesting that the frequency of interactions can also be a factor in honeybee survival.

Survival was also affected by the density of bees in cage experiments, with higher survival in smaller groups (10-60 individuals), than in groups of 100-180 individuals. A different trend was found by Rinderer and Baxter (1978), where groups of 10-20 individuals had much lower survival than groups of 30-100 individuals, and survival did not differ significantly between groups once the density increased about 30 bees per cage, suggesting that there is a minimum density required in order to maintain the social interactions that can affect survival in honeybees. The most observable difference between the groups with fewer individuals and those with more individuals in our experiment was cage fouling, with the cages becoming dirtier at higher densities. Ventilation is essential for maintaining internal conditions such as temperature, humidity and oxygen levels inside the hive (Oertel 1949; Human et al. 2006; Ellis et al. 2010). Cage fouling could have reduce the ventilation but that is unlikely since one would expect that in both experiments, the mortality increases with decreasing volume per bee, which is not the case (Table I). The sides of the cages became caked with dried diet which the bees seem to remove without consuming, and without having a place to store it. As a result, consumption values could be overestimated in high densities of bees. Caged honeybees may store diets when comb is provided and then consume the stored diets instead of the fresh diet in feeders (Köhler et al. 2012, 2013). The amount of stored diet is also affected by the properties of the diet: less sucrose solution was stored when it had a higher nicotine concentration (Köhler et al. 2012), and our experiment would suggest that higher honeybee density is another factor that influences diet storage. Rinderer and Baxter (1978) also showed that groups of 1020 bees hoarded less diet in comb than groups of 30-50, and that groups of 100 hoarded the most diet. A trend of reduced consumption in bigger groups has been observed under natural hive conditions, where in winter consumption per bee decreased as colony size increased, without affecting the survival (Free and Racey 1968).

In the cages with the three highest densities of bees (100 bees and more per cage), the bees produced new wax which coated the sides of the cage. This is an example of a social interaction that requires certain group sizes of bees (see Table 6.1 in Hepburn et al. 2014). We have previously observed wax building in caged honeybees kept in groups of 100, which manipulated the wax sheet provided by building additional cells (Altaye et al. 2010). The presence of wax can influence bee behaviour in the hive and can trigger temporal polyethism. Wax deprivation induces bees to abandon nurse bee duties and become foragers or wax producers (Fergusson and Winston 1988). Wax has an important role in the hive; in addition to being used as a substrate to store nutrients and house brood, it also absorbs cues and food scents in the same manner as the hydrocarbon-based cuticle of workers, which then aids in nest mate recognition of returning foragers (Breed et al. 1988). Experimental designs sometimes include adding a piece of wax to the cage, in the form of either wax sheeting or wax comb removed from the hives (Altaye et al. 2010; Köhler et al. 2013; Archer et al. 2014a, b). The addition of wax to the cage seems to increase 
survival, but bees will also use this space to store some of the diet they were given, and if consumption is measured, this may skew the results (Köhler et al. 2013).

The seeming contradiction that the highest survival was found on the lower densities of bees as well as the smallest cages suggests that it is not only the volume per bee that plays a role, but also the social interactions and the cumulative effect of cage fouling. Two factors differed between highdensity cages and large cages with a low volume per bee, namely cage fouling and wax production. Cage fouling due to hoarding behaviour was observed in the high densities of bees, but not in the small cages, even though in both situations, the available volume per bee was low $(<3 \mathrm{ml}$ bee) . This does not necessarily mean that the bees hoard more at higher densities, but that there are more bees hoarding at the same rate. Rinderer and Baxter (1978) observed that the comb in cages of 100 bees contained more hoarded diet than the other group sizes, even though they hoarded diet at similar rates. Therefore, even though bees are in close proximity to each other in both the highest densities and the smallest cage volumes, more diet and more feeders were available to more bees in the high-density experiment than in the cage size experiments and this could have caused cage fouling, and subsequent reduced ventilation, to become a significant factor in reducing survival. Since wax production requires groups of 100 or more bees (Hepburn et al. 2014), this was observed only in the high densities and not in the low volume experiment, although once again the bees were in close proximity to each other in both situations. The energetic cost of producing wax (Hepburn et al. 2014) could contribute to the reduced survival in the high densities and explain why the bees in the small cages did not suffer the same adverse effects.

We have shown that cage volumes that allow bees the same amount of space as naturally selected nest sites yielded the best survival. We have also shown that while bees prefer to be in close proximity to each other, large group sizes in the laboratory will lead to different social interactions that should be taken into consideration. Honeybees will try and adapt their environment around their requirements by thermoregulation or wax building, and will suffer increased mortality when they are unable to do so.

\section{AUTHOR CONTRIBUTIONS}

HJB, SWN and CWWP conceived this research and designed experiments; CRA and CWWP participated in the design and interpretation of the data; HJB performed experiments and analysis; all authors wrote and revised the paper. All authors read and approved the final manuscript.

\section{FUNDING INFORMATION}

This work was funded jointly by a grant from the BBSRC, NERC, the Welcome Trust, Defra, and the Scottish Government under the Insect Pollinators Initiative (BB/I000968/1). Additional support came from the South African National Research Foundation and the University of Pretoria.

\section{COMPLIANCE WITH ETHICAL STANDARDS}

Conflict of interest The authors declare that they have no conflict of interest.

Effets du volume de la cage et de la densité des abeilles sur la survie et la consommation en nutriments des abeilles (Apis mellifera L.) en laboratoire conception de la cage /études de laboratoire/régulation des nutriments/survie/abeilles

Einfluß des Käfigvolumens und der Bienendichte auf das Überleben und die Futteraufnahme von Honigbienen (Apis mellifera) unter Laborbedingungen

Käfigaufbau / Laborstudien / Nährstoffregulation /
Überleben / Honigbienen

\section{REFERENCES}

Altaye, S.Z., Pirk, C.W.W., Crewe, R.M. \& Nicolson, S.W. (2010). Convergence of carbohydrate-biased intake targets in caged honeybees fed different protein types. J. Exp. Biol. 213, 3311-3318.

Archer, C.R., Pirk, C.W.W., Wright, G.A. \& Nicolson, S.W. (2014a). Nutrition affects survival in African 
honeybees exposed to interacting stressors. Funct. Ecol. 28, 913923.

Archer, C.R., Kohler, A., Pirk, C.W.W., Oosthuizen, Apostolides, Z., Nicolson, S.W. (2014b). Antioxidant supplementation can reduce the survival cost of excess amino acid intake in honeybees. J. Insect. Physiol. 71, 78-86.

Basile, R., Pirk, C.W.W. \& Tautz, J. (2008). Trophallactic activities in the honeybee brood nest-heaters get supplied with high performance fuel. Zool. 111, 433-441.

Bosua, H.J. 2017. Optimising honeybee (Apis mellifera scutelata: Lepeletier), performance in laboratory conditions: effects of diet state, cage volume and bee density on survival and nutrient regulation. Unpublished MSc Thesis, University of Pretoria, Pretoria, South Africa.

Breed, M.D., Williams, K.R. \& Fewell, J.H. (1988). Comb wax mediates the acquisition of nest-mate recognition cues in honey bees. Popul. Biol. 85, 8766-8769.

Brodschneider, R., Libor, A., Kupelwieser \& Crailsheim, K. (2017). Food consumption and food exchange of caged honey bees using a radioactive labelled sugar solution. PLoS ONE 12, e0174684.

Camazine, S., Crailsheim, K., Hrassnigg, N., Robinson, G.E., Leonhard, B. \& Kropiunigg, H. (1998). Protein trophallaxis and the regulation of pollen foraging by honey bees (Apis mellifera L. ). Apidologie 29, 113-126.

Crailsheim, K. (1992). The flow of jelly within a honeybee colony. J. Comp. Physiol. B 162, 681-689.

Crane, E. (1994).Beekeeping in the World of Ancient Rome. Bee World 75, 118-134.

Ellis, M., Nicolson, S., Crewe, R., and Dietemann, V. (2010). Brood comb as a humidity buffer in honeybee nests. Naturwissenschaften 97, 429-433.

Fergusson, L.A. \& Winston, M.L. (1988). The influence of wax deprivation on temporal polyethism in honey bee (Apis mellifera L.) colonies. Can. J. Zool. 66, 19972001.

Free, J.B. \& Racey, P.A. (1968). The effect of the size of honeybee colonies on food consumption, brood rearing and the longevity of the bees during winter. Entomol. Exp. Appl. 11, 241-249.

Harrison J.M. (1987). Roles of individual honeybee workers and drones in colonial thermogenesis. J. Exp. Biol. 129, 53-61.

Hepburn, H.R., Pirk, C.W.W \& Duangphakdee, O. (2014). Honeybee nests: Composition, structure, function. Springer Science \& Business Media.

Howard, K.J. \& Thorne, B.L. (2010). Eusocial evolution in termites and Hymenoptera. In: Biology of Termites: a modern synthesis. Springer Netherlands; 2010 pp 97132.

Huang, Z. \& Robinson, G.E. (1992). Honeybee colony integration: worker-worker interactions mediate hormonally regulated plasticity in division of labour. Pop. Biol. 89, 11726-11729.

Huang, S.K., Csaki, T., Doublet, V., Dussaubat, C., Evans, J.D., Gajda, A.M., Gregorc, A., Hamilton, M.C.,
Kamler, M., Lecocq, A., Muz, M.N., Neumann, P., Ozkirim, A., Schiesser, A., Sohr, A.R., Tanner, G., Tozkar, C.O., Williams, G.R., Wu, L., Zheng, H. \& Chen, Y.P. (2014). Evaluation of cage designs and feeding regimes for honey bee (Hymenoptera: Apidae) laboratory experiments. J. Econ. Entomol. 107, 54 62.

Human, H., Nicolson, S.W. \& Dietemann, V. (2006). Do honeybees, Apis mellifera scutelata, regulate humidity in the nest? Naturwissenschaften 93, 397-401.

Jones, J.C., Myerscough, M.R., Graham, S. \& Oldroyd, B.P. (2004). Honey bee nest thermoregulation: diversity promotes stability. Science $\mathbf{3 0 5}, 402-404$.

Köhler, A., Pirk, C.W.W. \& Nicolson, S.W. (2012). Honeybees and nectar nicotine: deterrence and reduced survival versus potential health benefits. J. Insect. Phys. 58, 268-292.

Köhler, A., Nicolson, S.W. \& Pirk, C.W.W. (2013). A new design for honeybee hoarding cages for laboratory experiments. J. Apic. Res. 52, 12-14.

Lindauer, M. (1955). The water economy and temperature regulation of the honeybee colony. Bee World 36, 8192.

McMenamin, A., Mumoki, F., Frazier, M., Kilonzo, J., Mweu, B., Baumgarten, T., Patch, H., Torto, B., Masiga, D., Tumlinson, J., Gronzinger, C. \& Muli, E. (2017). The impact of hive type on the behaviour and health of honeybee colonies in Kenya. Apidologie DOI: https://doi.org/10.1007/s13592-017-0515-5.

McNally, L.C. \& Schneider, S.S. (1996). Spatial distribution and nesting biology of colonies of the african honey bee Apis mellifera scutellata (Hymenoptera: Apidae) in Botswana, Africa. Pop. Ecol. 25, 643-652.

Morais, M.M., Turcatto, A.P., Pereira, R.A., Francoy, T.M., Guidugli-Lazzarini, K.R., Conclaves, L.S., de Almeida, J.M.V., Ellis, J.D. \& De Jong, D. (2013). Protein levels and colony development of Africanized and European honeybees fed natural and artificial diets. Gen.Mol. Res. 12, 6915-6922.

Nowak, M.A., Tarnita, C.E. \& Wilson, E.O. (2010). The evolution of eusociality. Nature 466, 1057-1062.

Oertel, E. (1949). Relative humidity and temperature within the beehive. J. Econ. Entomol. 42, 528-531.

Paoli, P.P., Donley, D., Stabler, D., Saseendranath, A., Nicolson, S.W., Simpson, S. J \& Wright, G.A. (2014). Nutritional balance of essential amino acids and carbohydrates of the adult worker bee depends on age. Amino Acids 46: 1449-1458.

Rinderer, T. E., \& Baxter, J.R. (1978). Honey bees: the effect of group size on longevity and hoarding in laboratory cages. Annu. Entomol. Soc. USA. 71, 732.

Schott, M. Bischoff, G. Eichner, G., Vilcinskas, A., Buchler, R., Meixner, D. \& Brandt, A. (2017). Temporal dynamics of whole body residues of the neonicotinoid insecticide imidacloprid in live or dead honeybees. Sci. Report. 7, doi:https://doi.org/10.1038 /s41598-017-06259-Z

Seeley, T. \& Morse, R. (1976). The nest of the honey bee (Apis mellifera L.). Insectes Sociaux 23, 495-512. 
Vaudo, A.D., Ellis, J.D., Cambray, G.A., Hill, M. (2012). Honey bee (Apis mellifera capensis/A. m. scutellata hybrid) nesting behavior in the Eastern Cape, South Africa. Insectes Sociaux. 59, 323-331.

von Frisch, K. \& Lindauer, M. (1956). The language and orientation of the honeybee. Annu. Rev. Entomol. 1, 45-58.

Williams, G. R, Alaux, C., Costa, C., Cáski, T., Doublet, V., Eisenhardt, D., Fries, I., Kuhn, R., Mcmahon, D.P.,
Medrzycki, P., Murray, T.E., Natsopoulou, M.E., Neumann, P., Oliver, R., Paxton, R.J., Pernal, S.F., Shutler, D., Tanner, G., Van Der Steen, J.J.M., Brodschneider, R. (2013). Standard methods for maintaining adult Apis mellifera in cages under in vitro laboratory conditions. J. Apicult. Res. 52, 1-4.

Winston, M.L. \& Michener, C.D. (1977). Dual origin of highly social behaviour among bees. Proc. Natl. Acad. Sci. USA 74, 1135-1137. 